\title{
Detection of a dry-frozen boundary inside Martian regolith
}

\author{
Fabio Gori ${ }^{1}$, Sandra Corasaniti* \\ Mechanical Engineering Department, University of Rome "Tor Vergata", Via del Politecnico 1, 00133 Rome, Italy
}

Received 17 May 2007; received in revised form 4 February 2008; accepted 6 February 2008

Available online 17 February 2008

\begin{abstract}
The present work investigates the time oscillations of the temperature at several depths of a Martian soil analogue made of two layers of different physical properties. The maximum temperature-time oscillation inside the Martian soil analogue, DT, and its derivative with depth, $\mathrm{d}(\mathrm{DT}) / \mathrm{d} z$ or DDT, can be analysed to understand the presence of a boundary between dry and frozen soil. The maximum temperature-time oscillation, DT, reduces by about one order of magnitude at the boundary between dry and frozen soil if a frozen layer is present. The reduction of DT at the boundary between two dry soils with different porosity is much smaller. DDT decreases by more than one order of magnitude at the boundary between dry and frozen soil if a frozen layer is present. The reduction of DDT at the boundary between two dry soils with different porosity is much smaller.
\end{abstract}

(C) 2008 Elsevier Ltd. All rights reserved.

Keywords: Martian soil analogue; Thermal conductivity; Thermal diffusivity; Temperature measurement; Temperature oscillation

\section{Introduction}

The main objective of Martian exploration is the search of ice-water in the subsurface of Martian regolith. In the current Martian climate ice-water is not stable on the surface at low and mid-latitudes. Near-surface ground ice (subsurface ice in the upper metres of the surface) is an important component of the global cycles of water and of the behaviour of the Martian climate. It represents a substantial reservoir of water that can dynamically exchange with the atmosphere on timescales comparable to that of the oscillations in the planet orbit (Mellon et al., 2003). Some scientific instruments, like Mole for Soil Compositional Studies (MOCCS) instrument and electromechanical penetrating instrument, can obtain depth profiles of soil chemical, physical and thermal properties and can repeatedly obtain subsurface soil samples from depths up to $1.5 \mathrm{~m}$ to be used by land- or rover-based instruments (Richter et al., 2004). Mellon et al. (2004) calculated new estimates of ground-ice stability and the

\footnotetext{
${ }^{*}$ Corresponding author. Tel.: + 39672597130 ; fax: +3962021351.

E-mail addresses: gori@uniroma2.it (F. Gori), sandra.corasaniti@, uniroma2.it (S. Corasaniti).

${ }^{1}$ Tel.: + 39672597129 ; fax: +3962021351.
}

depth distribution of the ice table and compared these theoretical estimates of the ground ice with the observed distribution of leakage neutrons measured by the Mars Odyssey Gamma Ray Spectrometer (GRS). Observations by the Mars Odyssey spacecraft of abundant subsurface hydrogen in the Martian regolith indicated that shallowly buried ground ice (subsurface ice) is present in Martian southern mid- and high latitudes (Boynton et al., 2002; Feldman et al., 2002). GRS detected significant amounts of hydrogen in equatorial regions of Mars, within a couple of metres from the surface, indicating the presence of water-ice up to a depth of about $1 \mathrm{~m}$. Measurements indicate that the uppermost regolith contains a little amount of ice, while an ice-rich zone below can contain from $20 \%$ to $50 \%$ of ice by mass. A possible configuration in the upper surface of the Mars regolith provides at the Equator $\left(0^{\circ}\right.$ Latitude) a layer of dry soil (solid and gas) down to a depth of $1.30 \mathrm{~m}$ and a frozen soil (solid, gas and water-ice) below. At $60^{\circ}$ South of Latitude a layer of dry soil from 0 to $0.60 \mathrm{~m}$ of depth and a frozen soil below. At the South Pole $\left(90^{\circ}\right.$ South Latitude) a layer of dry soil (solid and gas) from 0 to $0.30 \mathrm{~m}$ of depth and a frozen soil below. Besides, it is unknown how deep the ice-rich zone continues below (Böttger et al., 2005). Neutron spectroscopy data acquired by Mars Odyssey were analysed to 


\section{Nomenclature}

\section{Latin letters}

$$
\begin{array}{ll}
a & \text { ice mass content, } \mathrm{kg} \mathrm{kg}^{-1} \\
C=\rho c & \text { thermal capacity, } \mathrm{J}(\mathrm{m} \mathrm{K})^{-1} \\
c & \text { specific heat, } \mathrm{w}(\mathrm{m} \mathrm{K})^{-1} \\
D=\sqrt{2 k / C \omega} \text { damping depth, } \mathrm{m} \\
\mathrm{DT} & \text { temperature variation with time, } \mathrm{K} \\
\mathrm{DDT} & \text { derivative of DT with depth, } \mathrm{K} \mathrm{m}^{-1} \\
d & \text { depth of upper layer, } \mathrm{m} \\
f & \text { saturation degree, dimensionless } \\
k & \text { thermal conductivity, } \mathrm{W}(\mathrm{m} \mathrm{K})^{-1} \\
M & \text { mass, kg } \\
t & \text { time, } \mathrm{s} \\
T & \text { temperature, } \mathrm{K}
\end{array}
$$

$$
z \quad \text { depth, } \mathrm{m}
$$

\section{Greek letters}

$$
\begin{array}{ll}
\alpha=k / \rho c & \text { thermal diffusivity, } \mathrm{m}^{2} \mathrm{~s}^{-1} \\
\rho & \text { density, } \mathrm{kg} \mathrm{m}^{-3} \\
\vartheta & \text { temperature, } \mathrm{K} \\
\omega & \text { radial frequency, } \mathrm{s}^{-1}
\end{array}
$$

\section{Subscripts}

$\begin{array}{ll}\text { i } & \text { ice } \\ 1 & \text { upper layer } \\ 2 & \text { lower layer } \\ \min & \text { minimum } \\ \text { max } & \text { maximum }\end{array}$

determine the abundance and depth of near-surface water-ice as a function of latitude in the Southern Hemisphere (Prettyman et al., 2004).

The lack of information on the thermal properties and the structure of Martian regolith (including the presence of ice layers) motivated the present line of investigation. One aspect of the present work is the theoretical prediction of the thermal conductivity of extraterrestrial soils, as those of planets and comets, on the basis of the knowledge of the physical parameters. Theoretical predictions of Earth soils, subject to permafrost conditions, were carried out with reference to a four-phase medium, i.e. in presence of solid, ice, water and air (Gori, 1983). The model is based on the assumption of the soil as a unit cell with a cubic particle at the centre and the other three phases disposed around it according to the laws of adsorption and capillarity. The original cubic cell model was extended to take into account - different thermal boundary conditions (Gori and Corasaniti, 1999), thermal radiation and low density (high porosity) in extraterrestrial conditions (Gori and Corasaniti, 2001). The original cubic cell model has been compared with other models of the literature (Tarnawski and Gori, 2002).

In conclusion, the cubic cell model can be considered as a valid approach to predict the thermal conductivity of soils in extraterrestrial bodies where the physical conditions can be different from that of the Earth, as far as pressure, temperature, fluids in the atmosphere are concerned, and where also thermal radiation can be taken into consideration. The theoretical model can correlate the structure of the soil to the materials present (in solid or vapour phase).

The soil close to the atmosphere has the lowest thermal conductivity during the hottest period of the day because the materials are present only in vapour phase. The presence of ice layers increases the thermal conductivity of the soil because of its higher thermal conductivity. The present work investigates three Martian soil analogues, which are based on the information obtained at $0^{\circ}, 60^{\circ}$ and $90^{\circ}$ of Latitude.

\section{Thermal properties of a Martian soil analogue}

\subsection{Martian soil analogue and atmospheric gas}

The solid component of the Martian soil analogue is simulated using the thermal conductivity of the olivine tested in laboratory (Gori and Corasaniti, 2003). Mars soil analogues, in dry and frozen conditions, have been investigated with the theoretical cubic cell model, (Gori and Corasaniti, 2004, 2006) and the relative data will be used in the rest of the present paper.

The average Martian atmospheric pressure is about 6 mbar (Presley and Christensen, 1997) and is composed of $\mathrm{CO}_{2}(95 \%), \mathrm{N}_{2}(3 \%), \mathrm{Ar}(1.5 \%)$ and tracks of $\mathrm{H}_{2} \mathrm{O}$. The thermal conductivity of the Martian atmospheric gas is assumed to be $92.8 \%$ of the atmospheric pressure value (1 bar).

\subsection{Martian soils analogues}

Three Martian soil analogues are investigated:

(a) At the Equator $\left(0^{\circ}\right.$ Latitude):

- The dry soil (solid and gas) is present from 0 to $1.30 \mathrm{~m}$ of depth.

- The frozen soil (solid, gas and water-ice) extends below $1.30 \mathrm{~m}$.

(b) At $60^{\circ}$ South of Latitude:

- The dry soil (solid and gas) is present from 0 to $0.60 \mathrm{~m}$ of depth.

- The frozen soil (solid, gas and water-ice) extends below $0.60 \mathrm{~m}$.

(c) At the South Pole $\left(90^{\circ}\right.$ South Latitude):

- The dry soil (solid and gas) is present from 0 to $0.30 \mathrm{~m}$ of depth.

- The frozen soil (solid, gas and water-ice) extends below $0.30 \mathrm{~m}$. 
Ice mass content, $a=M_{\mathrm{i}} / M_{\mathrm{t}}$, is related to the soil porosity, $p$, for a water-ice saturated soil, as reported in Table 1 at several temperatures. The input parameter can be ice content, $a$, as shown in the first part of Table 1, or porosity, $p$, as shown in the second part.

\section{Temperature oscillations in a two-layer Martian soil analogue}

The Martian soil analogue is composed of two layers where the upper layer is present up to a depth $d$ while the lower one extends from $d$ to infinity. The differential heat conduction equation for a homogeneous medium, with $k$ independent of $z$, is

$\frac{\partial \vartheta}{\partial t}=\alpha \frac{\partial^{2} \vartheta}{\partial z^{2}}$

where $\theta$ is the temperature in $\mathrm{K}, t$ the time, $z$ the depth, $\alpha=k / \rho \cdot c$ the thermal diffusivity, $k$ the thermal conductivity, $\rho$ the density, $c$ the specific heat.

At each depth the temperature oscillates as a pure harmonic function of time, caused by the day-night oscillation, around an average value.

The differential equation is solved with the following boundary conditions (Van Wijk, 1963):

(1) The surface temperature (at $z=0$ ) is oscillating according to

$$
\vartheta(0, t)=\vartheta_{\mathrm{a}}+\vartheta_{\mathrm{s}} \sin (\omega t)
$$

(2) The continuity of temperature at the boundary between the two layers, $z=d$, is

$\vartheta_{1}(d, t)=\vartheta_{2}(d, t)$

where the subscript 1 is referred to the upper layer and the subscript 2 to the lower layer.

Table 1

Corresponding values of porosity, $p$, and ice content, $a$, for saturated frozen soils

Porosity, $p$, for frozen soil $(f=1)$

\begin{tabular}{lllll}
\hline$a=M_{\mathrm{i}} / M_{\mathrm{t}}$ & $p(T=148 \mathrm{~K})$ & $p(T=173 \mathrm{~K})$ & $p(T=223 \mathrm{~K})$ & $p(T=273 \mathrm{~K})$ \\
\hline 0.05 & 0.141 & 0.141 & 0.142 & 0.143 \\
0.10 & 0.257 & 0.258 & 0.259 & 0.260 \\
0.15 & 0.355 & 0.355 & 0.356 & 0.358 \\
0.20 & 0.438 & 0.439 & 0.440 & 0.442 \\
0.30 & 0.572 & 0.572 & 0.574 & 0.575 \\
0.40 & 0.675 & 0.676 & 0.677 & 0.678 \\
0.50 & 0.757 & 0.758 & 0.758 & 0.760
\end{tabular}

Ice content, $a$, for frozen soil $(f=1)$

\begin{tabular}{lllll}
\hline$p$ & $a(T=148 \mathrm{~K})$ & $a(T=173 \mathrm{~K})$ & $a(T=223 \mathrm{~K})$ & $a(T=273 \mathrm{~K})$ \\
\hline 0.20 & 0.074 & 0.074 & 0.074 & 0.073 \\
0.30 & 0.121 & 0.121 & 0.120 & 0.119 \\
0.40 & 0.176 & 0.176 & 0.175 & 0.174 \\
0.50 & 0.243 & 0.242 & 0.242 & 0.240 \\
\hline
\end{tabular}

(3) The continuity of the heat flux at the boundary between the two layers, $z=d$, is

$$
-k_{1}\left(\frac{\partial \vartheta_{1}(z, t)}{\partial z}\right)_{z=d}=-k_{2}\left(\frac{\partial \vartheta_{2}(z, t)}{\partial z}\right)_{z=d}
$$

(4) The temperature oscillations decrease to zero at an infinite depth

$$
\lim _{z \rightarrow \infty} \vartheta_{2}=\vartheta_{\mathrm{a}}
$$

The temperature oscillation in the upper layer, $0 \leqslant z \leqslant d$, is given by

$$
\begin{aligned}
\vartheta_{1}(z, t)= & \vartheta_{\mathrm{a}}+\vartheta_{1}^{\prime} \exp \left(-\frac{z}{D_{1}}\right) \sin \left(\omega t-\frac{z}{D_{1}}+\varphi_{1}^{\prime}\right) \\
& +\vartheta_{1}^{\prime \prime} \exp \left(\frac{z}{D_{1}}\right) \sin \left(\omega t+\frac{z}{D_{1}}+\varphi_{1}^{\prime \prime}\right)
\end{aligned}
$$

and in the lower layer, $z \geqslant d$, by

$\vartheta_{2}(z, t)=\vartheta_{\mathrm{a}}+\vartheta_{2}^{\prime} \exp \left(-\frac{z-d}{D_{2}}\right) \sin \left(\omega t-\frac{z-d}{D_{2}}+\varphi_{2}\right)$

where $\vartheta_{\mathrm{a}}$ is the average temperature in the soil analogue, $\vartheta_{\mathrm{s}}$ is the amplitude of the temperature oscillation at the surface, $t$ is the time, $d$ is the thickness of the upper layer, $\varphi$ is the phase delay, $k_{1}$ is the thermal conductivity of the upper layer, $C_{1}$ is the heat capacity of the upper layer, $k_{2}$ is the thermal conductivity of the lower layer, $C_{2}$ is the heat capacity of the lower layer.

Further on $D_{1}$ and $D_{2}$ are the damping depths in $\mathrm{m}$ of the two layers:

$$
D_{1}=\sqrt{\frac{2 k_{1}}{C_{1} \omega}}
$$

$D_{2}=\sqrt{\frac{2 k_{2}}{C_{2} \omega}}$

The radial frequency is $\omega=2 \pi / T=2 \pi / 86400=7.27 \times$ $10^{-5} \mathrm{~s}^{-1}$ under the assumption of a Martian day of $24 \mathrm{~h}$.

Finally

$$
\begin{aligned}
\vartheta_{1}^{\prime}= & \vartheta_{\mathrm{s}}\left[1+r_{1}^{2} \exp \left(-\frac{4 d}{D_{1}}\right)\right. \\
& \left.+2 r_{1} \exp \left(-\frac{2 d}{D_{1}}\right) \cos \left(\frac{2 d}{D_{1}}\right)\right]^{-1 / 2}
\end{aligned}
$$

$\vartheta_{1}^{\prime \prime}=\vartheta_{1}^{\prime} r_{1} \exp \left(-\frac{2 d}{D_{1}}\right)$

$\vartheta_{2}^{\prime}=\vartheta_{1}^{\prime}\left(1+r_{1}\right) \exp \left(-\frac{d}{D_{1}}\right)$ 
$\varphi_{1}^{\prime}=\arctan \left(\frac{r_{1} \exp \left(-\left(2 d / D_{1}\right)\right) \sin \left(2 d / D_{1}\right)}{1+r_{1} \exp \left(-\left(2 d / D_{1}\right)\right) \cos \left(2 d / D_{1}\right)}\right)$

$\varphi_{1}^{\prime \prime}=\varphi_{1}^{\prime}-\left(\frac{2 d}{D_{1}}\right)$

$\varphi_{2}=\varphi_{1}^{\prime}-\left(\frac{d}{D_{1}}\right)$

$r_{1}=\frac{\sqrt{k_{1} C_{1}}-\sqrt{k_{2} C_{2}}}{\sqrt{k_{1} C_{1}}+\sqrt{k_{2} C_{2}}}$

\section{Temperature oscillations in a two-layer Martian soil analogue}

The soil analogues investigated in the present work are named soils A and B if they are composed of a dry layer on top and a frozen one below, or soil BA if they are composed of two dry layers with different properties.

\subsection{Soils $A$}

The soils $\mathrm{A}$, named $\mathrm{A} 1, \mathrm{~A} 2$ and $\mathrm{A} 3$ according to the thickness $d$ of the dry soil, i.e. $0.30 \mathrm{~m}$ for A1, $0.60 \mathrm{~m}$ for A2 and $1.30 \mathrm{~m}$ for $\mathrm{A} 3$, have the properties reported in Table 2 where the thermal conductivity is evaluated according to the cubic cell model (Gori and Corasaniti, 2004, 2006). The dry layer, with porosity $p=0.20$, has a thermal conductivity equal to $0.144 \mathrm{~W}(\mathrm{~m} \mathrm{~K})^{-1}$ and a thermal diffusivity equal to $10^{-6} \mathrm{~m}^{2} \mathrm{~s}^{-1}$. The frozen layer, with porosity $p=0.20$, has a thermal conductivity equal to $2.70 \mathrm{~W}(\mathrm{~m} \mathrm{~K})^{-1}$ and a thermal diffusivity equal to $10^{-5} \mathrm{~m}^{2} \mathrm{~s}^{-1}$.

\subsubsection{Soil A1}

Soil A1 simulates the Martian regolith at the Pole, which is assumed dry up to $d=0.30 \mathrm{~m}$ and frozen below.

Table 2

Characteristics of soil analogues A, B and BA

\begin{tabular}{llllll}
\hline & Soil $(\mathrm{m})$ & $f$ & $k\left(\mathrm{~W}(\mathrm{~m} \mathrm{~K})^{-1}\right)$ & $\alpha\left(\mathrm{m}^{2} \mathrm{~s}^{-1}\right)$ & $p$ \\
\hline A1 & $0-0.30$ & 0 & 0.144 & $10^{-6}$ & 0.20 \\
A1 & Below 0.30 & 1 & 2.70 & $10^{-5}$ & 0.20 \\
A2 & $0-0.30$ & 0 & 0.144 & $10^{-6}$ & 0.20 \\
A2 & Below 0.30 & 1 & 2.70 & $10^{-5}$ & 0.20 \\
A3 & $0-0.30$ & 0 & 0.144 & $10^{-6}$ & 0.20 \\
A3 & Below 0.30 & 1 & 2.70 & $10^{-5}$ & 0.20 \\
B1 & $0-0.30$ & 0 & 0.05 & $10^{-6}$ & 0.50 \\
B1 & Below 0.30 & 1 & 2.70 & $10^{-5}$ & 0.50 \\
B2 & $0-0.30$ & 0 & 0.05 & $10^{-6}$ & 0.50 \\
B2 & Below 0.30 & 1 & 2.70 & $10^{-5}$ & 0.50 \\
B3 & $0-0.30$ & 0 & 0.05 & $10^{-6}$ & 0.50 \\
B3 & Below 0.30 & 1 & 2.70 & $10^{-5}$ & 0.50 \\
BA1 & $0-0.30$ & 0 & 0.05 & $10^{-6}$ & 0.50 \\
BA1 & Below 0.30 & 0 & 0.144 & $10^{-6}$ & 0.20 \\
BA2 & $0-0.30$ & 0 & 0.05 & $10^{-6}$ & 0.50 \\
BA2 & Below 0.30 & 0 & 0.144 & $10^{-6}$ & 0.20 \\
BA3 & $0-0.30$ & 0 & 0.05 & $10^{-6}$ & 0.50 \\
BA3 & Below 0.30 & 0 & 0.144 & $10^{-6}$ & 0.20 \\
\hline
\end{tabular}

Fig. 1 reports the temperature-time oscillations at several depths, evidencing the oscillations up to $0.30 \mathrm{~m}$ in the first semi-cycle and those below $0.30 \mathrm{~m}$ in the second semi-cycle. Fig. 1 shows that the temperature-time oscillations are higher in the upper layer, i.e. in the dry soil, because of the lower thermal conductivity and diffusivity. The higher thermal conductivity and diffusivity in the frozen layer of the soil analogue reduces the temperaturetime oscillations.

The maximum oscillations of the temperature are reported in Table 3. They are, respectively: $\mathrm{DT}=7 \mathrm{~K}$ at $0.30 \mathrm{~m}, \mathrm{DT}=4 \mathrm{~K}$ at $0.60 \mathrm{~m}$ and $\mathrm{DT}=1 \mathrm{~K}$ at $1.3 \mathrm{~m}$.

Fig. 2 reports the temperature versus the depth $z$ at several times. The temperature oscillations with time are smaller in the frozen layer, i.e. below $0.30 \mathrm{~m}$, because of the higher thermal conductivity and diffusivity of the frozen layer.

\subsubsection{Soil $A 2$}

Soil A2 simulates the Martian regolith at $60^{\circ}$ of the Latitude, which is assumed dry up to $d=0.60 \mathrm{~m}$ and frozen below.

The maximum oscillations of the temperature are reported in Table 3. They are, respectively: DT $=25.0 \mathrm{~K}$ at $0.30 \mathrm{~m}, \mathrm{DT}=1.2 \mathrm{~K}$ at $0.60 \mathrm{~m}$ and $\mathrm{DT}=0.3 \mathrm{~K}$ at $1.3 \mathrm{~m}$.

Fig. 3 reports the temperature versus the depth $z$ at several times. The temperature oscillations with time are smaller in the frozen layer, i.e. below $0.60 \mathrm{~m}$, because of the higher thermal conductivity and diffusivity of the frozen layer.

\subsubsection{Soil A3}

Soil A3 simulates the Martian regolith at the Equator, which is assumed dry up to $d=1.30 \mathrm{~m}$ and frozen below.

The maximum oscillations of the temperature are reported in Table 3. They are, respectively: DT $=24.6 \mathrm{~K}$ at $0.30 \mathrm{~m}, \mathrm{DT}=4.0 \mathrm{~K}$ at $0.60 \mathrm{~m}$ and DT $=0.02 \mathrm{~K}$ at $1.3 \mathrm{~m}$.

\subsection{Soils $B$}

The soils $\mathrm{B}$, named $\mathrm{B} 1, \mathrm{~B} 2$ and $\mathrm{B} 3$ according to the thickness $d$ of the dry soil, i.e. $0.30 \mathrm{~m}$ for $\mathrm{B} 1,0.60 \mathrm{~m}$ for $\mathrm{B} 2$ and $1.30 \mathrm{~m}$ for $\mathrm{B} 3$, have the properties reported in Table 2 where the thermal conductivity has been evaluated according to the cubic cell model (Gori and Corasaniti, 2004, 2006). The dry layer, with porosity $p=0.50$, has the thermal conductivity equal to $0.05 \mathrm{~W}(\mathrm{~m} \mathrm{~K})^{-1}$ and the thermal diffusivity equal to $10^{-6} \mathrm{~m}^{2} \mathrm{~s}^{-1}$. The frozen layer, with porosity $p=0.50$, has the thermal conductivity equal to $2.70 \mathrm{~W}\left(\mathrm{~m} \mathrm{~K}^{-1}\right.$ and the thermal diffusivity equal to $10^{-5} \mathrm{~m}^{2} \mathrm{~s}^{-1}$.

\subsubsection{Soil BI}

Soil B1 simulates the Martian regolith at the Pole, which is assumed dry up to $d=0.30 \mathrm{~m}$ and frozen below. 


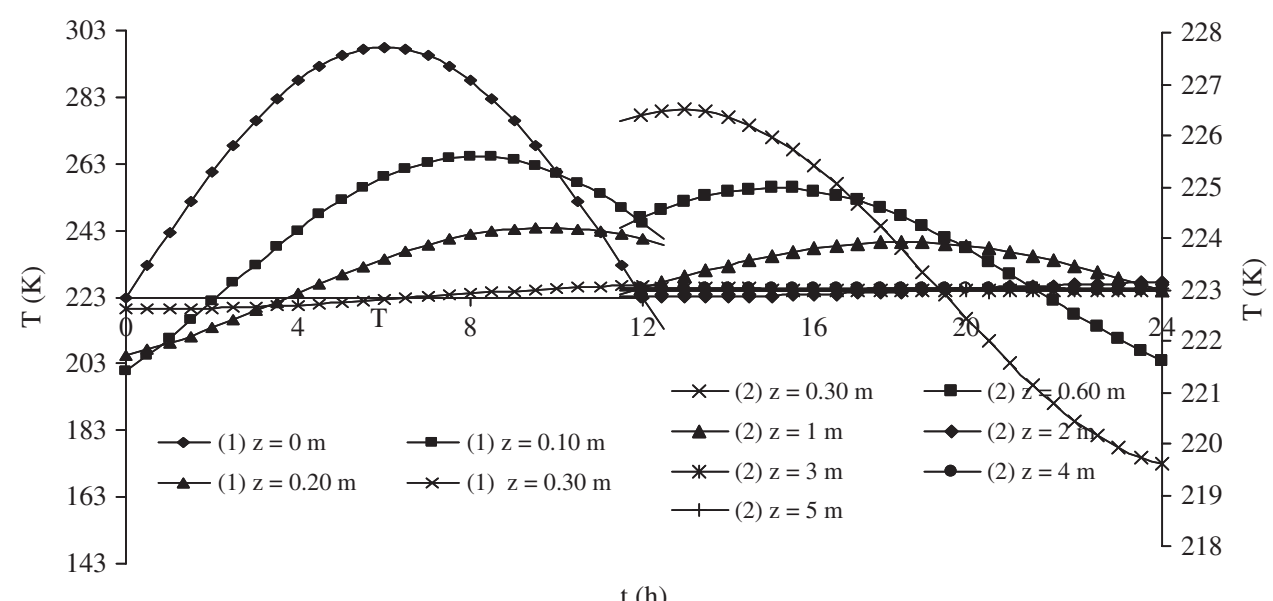

$\mathrm{t}(\mathrm{h})$

Fig. 1. Temperature-time oscillations in the soil analogue A1.

Table 3

Maximum temperature-time oscillations, $D T$, in soil analogues A at several depths

\begin{tabular}{llllll}
\hline$D T(\mathrm{~K})$ & Soil AF & Soil A1 & Soil A2 & Soil A3 & Soil AD \\
\hline$z(\mathrm{~m})$ & $d=0.00 \mathrm{~m}$ & $d=0.30 \mathrm{~m}$ & $d=0.60 \mathrm{~m}$ & $d=1.30 \mathrm{~m}$ & $d=5.00 \mathrm{~m}$ \\
\hline 0.00 & 150 & 150 & 150 & 150 & 150 \\
0.10 & 123.7 & 84.6 & 82 & 82 & 82 \\
0.20 & 102.4 & 41.7 & 44.9 & 44.9 & 44.9 \\
0.30 & 84.6 & 7 & 25 & 24.6 & 24.6 \\
0.40 & 69.9 & 5.8 & 14.1 & 13.4 & 13.4 \\
0.50 & 57.8 & 4.8 & 7 & 7.4 & 7.4 \\
0.60 & 47.7 & 4 & 1.2 & 4 & 4 \\
0.80 & 32.6 & 2.7 & 0.8 & 1.2 & 1.2 \\
1.00 & 22.2 & 1.8 & 0.5 & 0.4 & 0.4 \\
1.30 & 12.6 & 1 & 0.3 & 0.02 & 0.06 \\
2.00 & 3.3 & 0.3 & 0.08 & 0.005 & 0.0009 \\
3.00 & 0.5 & 0.04 & 0.01 & 0.0007 & 0 \\
4.00 & 0.07 & 0.006 & 0.002 & 0 & 0 \\
5.00 & 0.01 & 0.0009 & 0.0003 & 0 & 0 \\
\hline
\end{tabular}

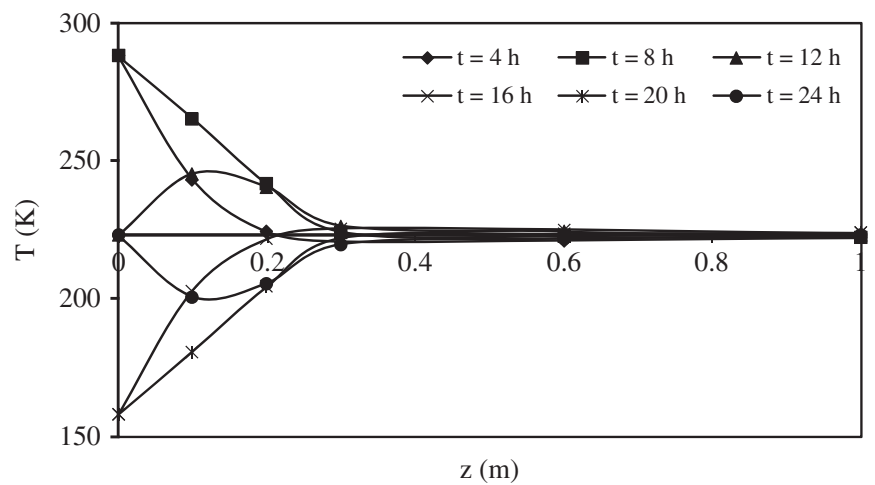

Fig. 2. Temperature-time oscillation, DT, versus depth in the soil analogue $\mathrm{A} 1$ at several different times.

The maximum oscillations of the temperature are reported in Table 4. They are, respectively: DT $=2.8 \mathrm{~K}$ at $0.30 \mathrm{~m}, \mathrm{DT}=1.6 \mathrm{~K}$ at $0.60 \mathrm{~m}$ and $\mathrm{DT}=0.4 \mathrm{~K}$ at $1.3 \mathrm{~m}$.

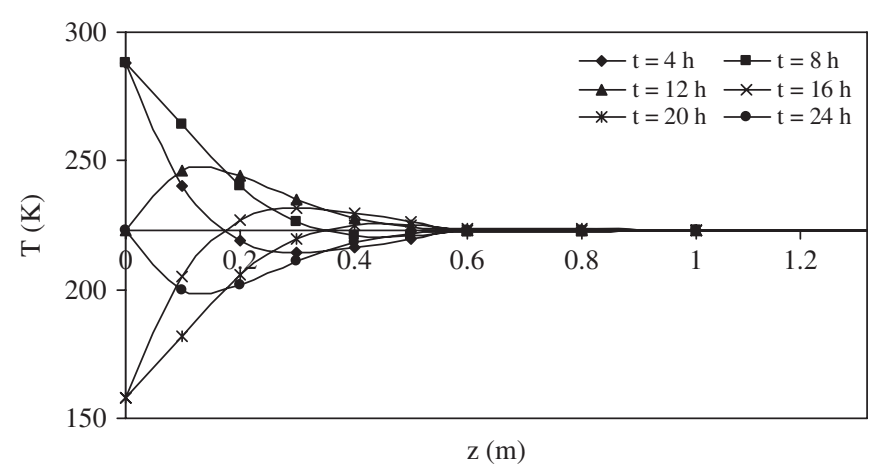

Fig. 3. Temperature-time oscillation, DT, versus depth in the soil analogue A2 at several different times.

Table 4

Maximum temperature-time oscillations, $D T$, in soil analogues $\mathrm{B}$ at several depths

\begin{tabular}{llllll}
\hline$D T(\mathrm{~K})$ & Soil BF & Soil B1 & Soil B2 & Soil B3 & Soil BD \\
\hline$z(\mathrm{~m})$ & $d=0.00 \mathrm{~m}$ & $d=0.30 \mathrm{~m}$ & $d=0.60 \mathrm{~m}$ & $d=1.30 \mathrm{~m}$ & $d=5.00 \mathrm{~m}$ \\
\hline 0.00 & 150 & 150 & 150 & 150 & 150 \\
0.10 & 123.7 & 85.2 & 81. & 81.9 & 81.9 \\
0.20 & 102.4 & 41.3 & 44.9 & 44.9 & 44.9 \\
0.30 & 84.5 & 2.8 & 25.1 & 24.6 & 24.6 \\
0.40 & 69.9 & 2.3 & 14.3 & 13.4 & 13.4 \\
0.50 & 57.8 & 1.9 & 6.9 & 7.3 & 7.3 \\
0.60 & 47.7 & 1.6 & 0.5 & 4 & 4 \\
0.80 & 32.6 & 1.1 & 0.3 & 1.2 & 1.2 \\
1.00 & 22.2 & 0.7 & 0.2 & 0.4 & 0.4 \\
1.30 & 12.6 & 0.4 & 0.1 & 0.01 & 0.06 \\
2.00 & 3.3 & 0.1 & 0.03 & 0.002 & 0.001 \\
3.00 & 0.5 & 0.02 & 0.005 & 0.0003 & 0 \\
4.00 & 0.07 & 0.002 & 0.0007 & 0 & 0 \\
5.00 & 0.01 & 0.0003 & 0.0001 & 0 & 0 \\
\hline
\end{tabular}

\subsubsection{Soil B2}

Soil B2 simulates the Martian regolith at $60^{\circ}$ of the Latitude, which is assumed dry up to $d=0.60 \mathrm{~m}$ and frozen below. 
The maximum oscillations of the temperature are reported in Table 4 . They are, respectively: DT $=25.1 \mathrm{~K}$ at $0.30 \mathrm{~m}, \mathrm{DT}=0.5 \mathrm{~K}$ at $0.60 \mathrm{~m}$ and $\mathrm{DT}=0.1 \mathrm{~K}$ at $1.3 \mathrm{~m}$.

\subsubsection{Soil B3}

Soil B3 simulates the Martian regolith at the Equator, which is assumed dry up to $d=1.30 \mathrm{~m}$ and frozen below.

The maximum oscillations of the temperature are reported in Table 4 . They are, respectively: DT $=24.6 \mathrm{~K}$ at $0.30 \mathrm{~m}, \mathrm{DT}=4.0 \mathrm{~K}$ at $0.60 \mathrm{~m}$ and DT $=0.01 \mathrm{~K}$ at $1.3 \mathrm{~m}$.

\subsection{Soils $B A$}

The Martian soil analogue, named soil BA and composed of two dry layers with different porosities, is investigated in order to point out the difference with the previous two soil analogues. The physical and thermal properties are reported in Table 2 . The thermal conductivity has been evaluated according to the cubic cell model (Gori and Corasaniti, 2004, 2006). The top dry layer, with porosity $p=0.50$, has the thermal conductivity equal to $0.05 \mathrm{~W}(\mathrm{~m} \mathrm{~K})^{-1}$ and the bottom dry layer, with porosity $p=0.20$, has the thermal conductivity equal to $0.144 \mathrm{~W}(\mathrm{~m} \mathrm{~K})^{-1}$. The thermal diffusivity is equal to $10^{-6} \mathrm{~m}^{2} \mathrm{~s}^{-1}$ for both layers.

\subsubsection{Soil BA1}

In the soil BA1 the upper layer is assumed to extend up to $0.30 \mathrm{~m}$ and the maximum temperature oscillations are reported in Table 5 . They are, respectively: $\mathrm{DT}=12.9 \mathrm{~K}$ at $0.30 \mathrm{~m}, \mathrm{DT}=2.1 \mathrm{~K}$ at $0.60 \mathrm{~m}$ and DT $=0.03 \mathrm{~K}$ at $1.3 \mathrm{~m}$.

\subsubsection{Soil $B A 2$}

In the soil BA2 the upper layer is assumed to extend up to $0.60 \mathrm{~m}$ and the maximum temperature oscillations are reported in Table 5 . They are, respectively: DT $=24.9 \mathrm{~K}$ at $0.30 \mathrm{~m}, \mathrm{DT}=2.1 \mathrm{~K}$ at $0.60 \mathrm{~m}$ and DT $=0.03 \mathrm{~K}$ at $1.3 \mathrm{~m}$.

Table 5

Maximum temperature-time oscillations, $D T$, in soil analogues BA at several depths

\begin{tabular}{lccccc}
\hline$D T(\mathrm{~K})$ & Soil AD & Soil BA1 & Soil BA2 & Soil BA3 & Soil BD \\
\hline$z(\mathrm{~m})$ & $d=0.00$ & $d=0.30$ & $d=0.60$ & $d=1.30$ & $d=5.00$ \\
\hline 0.00 & 150 & 150 & 150 & 150 & 150 \\
0.10 & 82 & 83.6 & 81.9 & 82 & 82 \\
0.20 & 44.9 & 42.5 & 44.9 & 44.9 & 44.9 \\
0.30 & 24.6 & 12.9 & 24.9 & 24.6 & 24.6 \\
0.40 & 13.4 & 7 & 13.9 & 13.4 & 13.4 \\
0.50 & 7.3 & 3.8 & 7 & 7.3 & 7.3 \\
0.60 & 4 & 2.1 & 2.1 & 4 & 4 \\
0.80 & 1.2 & 0.6 & 0.6 & 1.2 & 1.2 \\
1.00 & 0.4 & 0.2 & 0.2 & 0.4 & 0.4 \\
1.30 & 0.06 & 0.03 & 0.03 & 0.03 & 0.06 \\
2.00 & 0.0009 & 0.0004 & 0.0004 & 0.0004 & 0.0009 \\
3.00 & 0 & 0 & 0 & 0 & 0 \\
4.00 & 0 & 0 & 0 & 0 & 0 \\
5.00 & 0 & 0 & 0 & 0 & 0 \\
\hline
\end{tabular}

\subsubsection{Soil $B A 3$}

In the soil BA3 the upper layer is assumed to extend up to $1.30 \mathrm{~m}$ and the maximum temperature oscillations are reported in Table 5. They are, respectively: DT $=24.6 \mathrm{~K}$ at $0.30 \mathrm{~m}, \mathrm{DT}=4.0 \mathrm{~K}$ at $0.60 \mathrm{~m}$ and $\mathrm{DT}=0.03 \mathrm{~K}$ at $1.3 \mathrm{~m}$.

\section{Discussion on the temperature oscillations in a two-layer Martian soil analogue}

\subsection{Soils $A$}

The temperature-time oscillations in soils A are reported in Table 3 at several depths. The second and the last columns report the temperature-time oscillations in the frozen soil AF and in the dry soil AD. The temperaturetime oscillations are higher in soil AF at each depth because of the higher thermal conductivity and diffusivity of the frozen soil, while the temperature-time oscillations are lower in soil AD because of the lower thermal conductivity and diffusivity of the dry soil.

The maximum temperature-time oscillation, DT, reduces of about one order of magnitude at the boundary between dry and frozen soil, i.e. at $z=0.30,0.60$ and $1.30 \mathrm{~m}$, respectively, for soils A1, A2 and A3. In soil A1 the maximum temperature-time oscillation, DT, decreases from $41.7 \mathrm{~K}$ at $z=0.20 \mathrm{~m}$ to $7 \mathrm{~K}$ at $z=0.30 \mathrm{~m}$. In soil A2 the maximum temperature-time oscillation decreases from $7 \mathrm{~K}$ at $z=0.50 \mathrm{~m}$ to $1.2 \mathrm{~K}$ at $z=0.60 \mathrm{~m}$. In soil A3 the maximum temperature-time oscillation decreases from $0.4 \mathrm{~K}$ at $z=1.0 \mathrm{~m}$ to $0.02 \mathrm{~K}$ at $z=1.30 \mathrm{~m}$.

Fig. 4 reports the maximum temperature-time oscillations, DT, for soils A versus depth. A clear trend is evidenced, i.e. a decrease of the maximum temperaturetime oscillation with the increase of the layer $d$ of the dry soil over the frozen one.

\subsection{Soils $B$}

The maximum temperature-time oscillations in soils B are reported in Table 4 at several depths. The second and the last columns report the maximum temperature-time oscillation in the frozen soil BF and in the dry soil BD. The

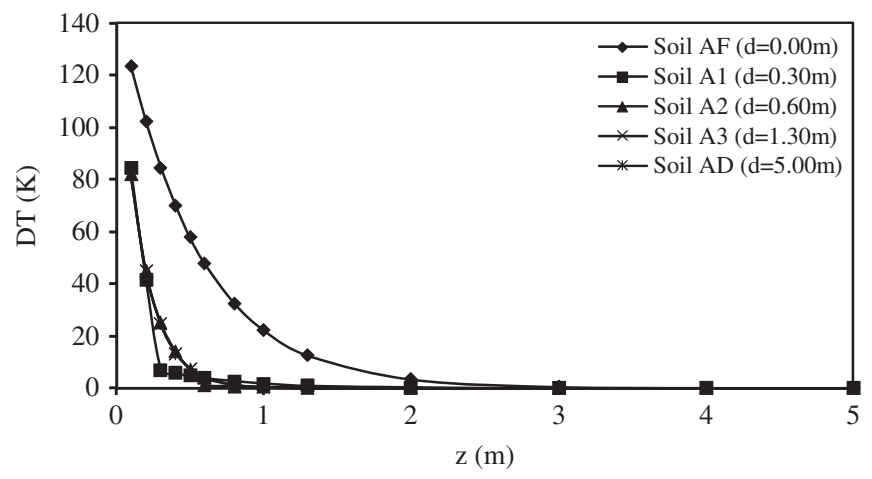

Fig. 4. Maximum temperature-time oscillation, DT, versus depth in the soil analogues $\mathrm{A}$ 
maximum temperature-time oscillation is higher in soil BF at each depth because of the higher thermal conductivity of the frozen soil. The maximum temperature-time oscillation is lower in soil BD at each depth because of the lower thermal conductivity of the dry soil.

The maximum temperature-time oscillation, DT, reduces of about one order of magnitude at the boundary between dry and frozen soil, i.e. at $z=0.30 \mathrm{~m}, z=0.60 \mathrm{~m}$ and $z=1.30 \mathrm{~m}$, respectively, for soil $\mathrm{B} 1, \mathrm{~B} 2$ and $\mathrm{B} 3$. In soil $\mathrm{B} 1$ the maximum temperature-time oscillation, DT, decreases from $41.3 \mathrm{~K}$ at $z=0.20 \mathrm{~m}$ to $2.8 \mathrm{~K}$ at $z=0.30 \mathrm{~m}$. In soil $\mathrm{B} 2$ the maximum temperature-time oscillation decreases from $6.9 \mathrm{~K}$ at $z=0.50 \mathrm{~m}$ to $0.5 \mathrm{~K}$ at $z=0.60 \mathrm{~m}$. In soil B3 the maximum temperature-time oscillation decreases from $0.4 \mathrm{~K}$ at $z=1.0 \mathrm{~m}$ to $0.01 \mathrm{~K}$ at $z=1.30 \mathrm{~m}$.

Fig. 5 reports the maximum temperature-time oscillation, DT, for soils $\mathrm{B}$ versus depth. The trend of the maximum temperature-time oscillation is to decrease with the increase of the layer $d$ of the dry soil.

\subsection{Soils $B A$}

The maximum temperature-time oscillations in soils BA are reported in Table 5 at several depths. The maximum temperature-time oscillation decreases from $42.5 \mathrm{~K}$ at $z=0.20 \mathrm{~m}$ to $12.9 \mathrm{~K}$ at $z=0.30 \mathrm{~m}$ for soil BA1, from $7 \mathrm{~K}$ at $z=0.50 \mathrm{~m}$ to $2.1 \mathrm{~K}$ at $z=0.60 \mathrm{~m}$ for soil $\mathrm{BA} 2$, from $0.4 \mathrm{~K}$ at $z=1.0 \mathrm{~m}$ to $0.03 \mathrm{~K}$ at $z=1.3 \mathrm{~m}$ for soil BA3.

Fig. 6 reports the maximum temperature-time oscillation, DT, for soils BA versus depth. The trend of the maximum temperature-time oscillation is different than in the other two soils (Figs. 4 and 5) because DT is independent of the layer $d$.

\section{Evaluation of the boundary dry-frozen soil and discussion}

The derivative of the maximum temperature-time oscillation with respect to the depth $z$, i.e. DDT $=\mathrm{d}(\mathrm{DT}) /$ $\mathrm{d} z\left(\mathrm{~K} \mathrm{~m}^{-1}\right)$, is given by

- in the upper layer, $0 \leqslant z \leqslant d$

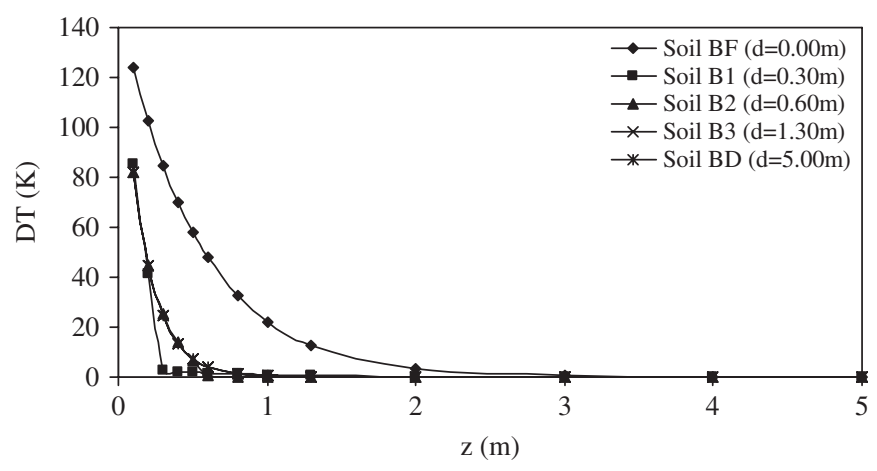

Fig. 5. Maximum temperature-time oscillation, DT, versus depth in the soil analogues B.

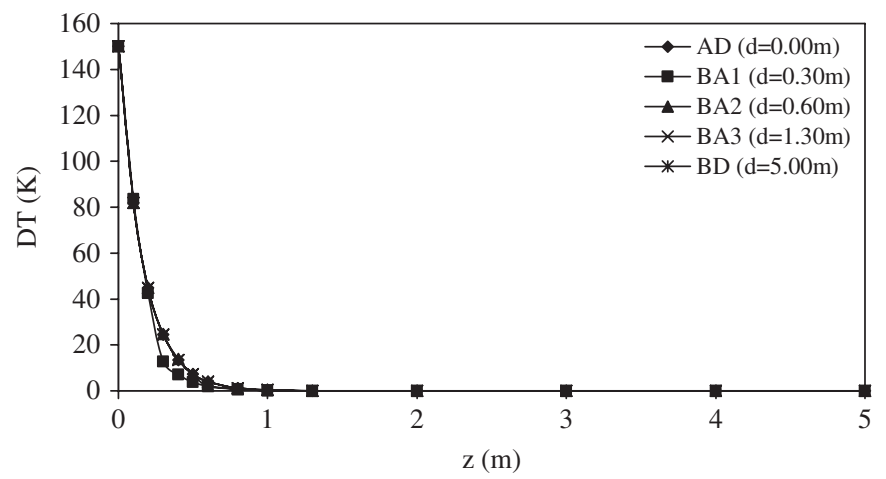

Fig. 6. Maximum temperature-time oscillation, DT, versus depth in the soil analogues BA.

$$
\begin{aligned}
\frac{\mathrm{d}\left(\vartheta_{1}-\vartheta_{\mathrm{a}}\right)}{\mathrm{d} z}=\operatorname{DDT}_{1}(z)= & \vartheta_{1}^{\prime}\left(-\frac{1}{D_{1}}\right) \exp \left(-\frac{z}{D_{1}}\right) \\
& \times\left[\sin \left(\omega t-\frac{z}{D_{1}}+\varphi_{1}^{\prime}\right)\right. \\
& \left.+\cos \left(\omega t-\frac{z}{D_{1}}+\varphi_{1}^{\prime}\right)\right] \\
& +\vartheta_{1}^{\prime \prime}\left(\frac{1}{D_{1}}\right) \exp \left(\frac{z}{D_{1}}\right) \\
& \times\left[\sin \left(\omega t+\frac{z}{D_{1}}+\varphi_{1}^{\prime \prime}\right)\right. \\
& \left.+\cos \left(\omega t+\frac{z}{D_{1}}+\varphi_{1}^{\prime \prime}\right)\right]
\end{aligned}
$$

- in the lower layer, $z \geqslant d$, by

$$
\begin{aligned}
\frac{\mathrm{d}\left(\vartheta_{2}-\vartheta_{\mathrm{a}}\right)}{\mathrm{d} z}= & \operatorname{DDT}_{2}(z)=\vartheta_{2}^{\prime}\left(-\frac{1}{D_{2}}\right) \\
& \times \exp \left(-\frac{z-d}{D_{2}}\right) \\
& \times\left[\sin \left(\omega t-\frac{z-d}{D_{2}}+\varphi_{2}\right)\right. \\
& \left.+\cos \left(\omega t-\frac{z-d}{D_{2}}+\varphi_{2}\right)\right]
\end{aligned}
$$

Tables 6-8 report DDT at several depths for the soils, A, $B$ and BA. Figs. 7-9 report DDT versus depth for the soils, $\mathrm{A}, \mathrm{B}$ and $\mathrm{BA}$.

\subsection{Soils $A$}

Table 6 reports the values of DDT at several depths for soils A. The values of DDT decrease with the depth $z$. At the boundary between dry and frozen soil DDT decreases from $356.3 \mathrm{~K} \mathrm{~m}^{-1}$ at $z=0.25 \mathrm{~m}$ to $12.9 \mathrm{~K} \mathrm{~m}^{-1}$ at $z=0.35 \mathrm{~m}$ for soil $\mathrm{A} 1$, from $59.1 \mathrm{~K} \mathrm{~m}^{-1}$ at $z=0.55 \mathrm{~m}$ to $2.1 \mathrm{~K} \mathrm{~m}^{-1}$ at $z=0.65 \mathrm{~m}$ for soil $\mathrm{A} 2$, and from $0.9 \mathrm{~K} \mathrm{~m}^{-1}$ at 
Table 6

Derivative of the maximum temperature-time oscillations, $D D T$, in soil analogues A at several depths

\begin{tabular}{|c|c|c|c|c|c|}
\hline$D D T\left(\mathrm{~K} \mathrm{~m}^{-1}\right)$ & Soil AF & Soil A1 & Soil A2 & Soil A3 & Soil AD \\
\hline$z(\mathrm{~m})$ & $d=0.00 \mathrm{~m}$ & $d=0.30 \mathrm{~m}$ & $d=0.60 \mathrm{~m}$ & $d=1.30 \mathrm{~m}$ & $d=5.00 \mathrm{~m}$ \\
\hline 0.05 & 250.6 & 657.4 & 696.4 & 695.1 & 695.1 \\
\hline 0.15 & 220.0 & 422.5 & 361.9 & 361.7 & 361.7 \\
\hline 0.25 & 169.1 & 356.3 & 184.5 & 187.2 & 187.2 \\
\hline 0.35 & 148.6 & 12.9 & 108.1 & 111.4 & 111.4 \\
\hline 0.45 & 114.0 & 9.9 & 69.8 & 57.8 & 57.8 \\
\hline 0.55 & 100.4 & 8.7 & 59.1 & 34.2 & 34.2 \\
\hline 0.65 & 87.7 & 6.7 & 2.1 & 17.8 & 17.8 \\
\hline 0.9 & 52.2 & 4.5 & 1.3 & 3.7 & 4.2 \\
\hline 1.2 & 30.8 & 2.4 & 0.7 & 0.9 & 0.7 \\
\hline 1.4 & 20.8 & 1.6 & 0.5 & $3 \mathrm{E}-02$ & $2 \mathrm{E}-01$ \\
\hline 2.5 & 2.6 & $2 \mathrm{E}-01$ & $6 \mathrm{E}-02$ & $3 \mathrm{E}-03$ & $3 E-04$ \\
\hline 3.5 & $4 \mathrm{E}-01$ & $3 E-02$ & $9 \mathrm{E}-03$ & $5 \mathrm{E}-04$ & $6 \mathrm{E}-07$ \\
\hline 4.5 & $5 \mathrm{E}-02$ & $4 \mathrm{E}-03$ & $1 \mathrm{E}-03$ & $8 \mathrm{E}-05$ & $2 \mathrm{E}-09$ \\
\hline
\end{tabular}

Table 7

Derivative of the maximum temperature-time oscillations, $D D T$, in soil analogues B at several depths

\begin{tabular}{llllll}
\hline$D D T\left(\mathrm{~K} \mathrm{~m}^{-1}\right)$ & Soil BF & Soil B1 & Soil B2 & Soil B3 & Soil BD \\
\hline$z(\mathrm{~m})$ & \multicolumn{1}{l}{$d=0.00 \mathrm{~m}$} & $d=0.30 \mathrm{~m}$ & $d=0.60 \mathrm{~m}$ & $d=1.30 \mathrm{~m}$ & $d=5.00 \mathrm{~m}$ \\
\hline 0.05 & 250.6 & 648.4 & 696.7 & 695.1 & 695.1 \\
0.15 & 220.0 & 426.4 & 361.9 & 361.7 & 361.7 \\
0.25 & 169.1 & 391.5 & 183.8 & 187.2 & 187.2 \\
0.35 & 148.6 & 5.1 & 107.2 & 111.4 & 111.4 \\
0.45 & 114.0 & 3.9 & 70.8 & 57.8 & 57.8 \\
0.55 & 100.4 & 3.4 & 65.4 & 34.2 & 34.2 \\
0.65 & 87.7 & 2.7 & 0.8 & 17.8 & 17.8 \\
0.9 & 52.2 & 1.8 & $5 \mathrm{E}-01$ & 3.7 & 4.2 \\
1.2 & 30.8 & 0.9 & $3 \mathrm{E}-01$ & 1.0 & 0.7 \\
1.4 & 20.8 & 0.6 & $2 \mathrm{E}-01$ & $1 \mathrm{E}-02$ & $2 \mathrm{E}-01$ \\
2.5 & 2.6 & $8 \mathrm{E}-02$ & $2 \mathrm{E}-02$ & $1 \mathrm{E}-03$ & $3 \mathrm{E}-04$ \\
3.5 & $4 \mathrm{E}-01$ & $1 \mathrm{E}-02$ & $3 \mathrm{E}-03$ & $2 \mathrm{E}-04$ & $6 \mathrm{E}-07$ \\
4.5 & $5 \mathrm{E}-02$ & $2 \mathrm{E}-03$ & $6 \mathrm{E}-04$ & $3 \mathrm{E}-05$ & $2 \mathrm{E}-09$ \\
\hline
\end{tabular}

Table 8

Derivative of the maximum temperature-time oscillations, $D D T$, in soil analogues BA at several depths

\begin{tabular}{llllll}
\hline$D D T\left(\mathrm{~K} \mathrm{~m}^{-1}\right)$ & Soil AD & Soil BA1 & Soil BA2 & Soil BA3 & Soil BD \\
\hline$z(\mathrm{~m})$ & $d=0.00 \mathrm{~m}$ & $d=0.30 \mathrm{~m}$ & $d=0.60 \mathrm{~m}$ & $d=1.30 \mathrm{~m}$ & $d=5.00 \mathrm{~m}$ \\
\hline 0.05 & 695.1 & 669.9 & 696.0 & 695.1 & 695.1 \\
0.15 & 361.7 & 417.3 & 361.8 & 361.7 & 361.7 \\
0.25 & 187.2 & 304.5 & 185.4 & 187.2 & 187.2 \\
0.35 & 111.4 & 57.9 & 109.2 & 111.4 & 111.4 \\
0.45 & 57.8 & 30.1 & 68.3 & 57.8 & 57.8 \\
0.55 & 34.2 & 17.8 & 50.0 & 34.2 & 34.2 \\
0.65 & 17.8 & 9.3 & 9.4 & 17.8 & 17.8 \\
0.9 & 4.2 & 2.2 & 2.2 & 4.2 & 4.2 \\
1.2 & 0.7 & 0.4 & 0.4 & 0.9 & 0.7 \\
1.4 & 0.2 & 0.1 & 0.1 & 0.1 & 0.2 \\
2.5 & $3 \mathrm{E}-04$ & $1 \mathrm{E}-04$ & $1 \mathrm{E}-04$ & $1 \mathrm{E}-04$ & $3 \mathrm{E}-04$ \\
3.5 & $6 \mathrm{E}-07$ & $3 \mathrm{E}-07$ & $3 \mathrm{E}-07$ & $3 \mathrm{E}-07$ & $6 \mathrm{E}-07$ \\
4.5 & $2 \mathrm{E}-09$ & $8 \mathrm{E}-10$ & $8 \mathrm{E}-10$ & $8 \mathrm{E}-10$ & $2 \mathrm{E}-09$ \\
\hline
\end{tabular}

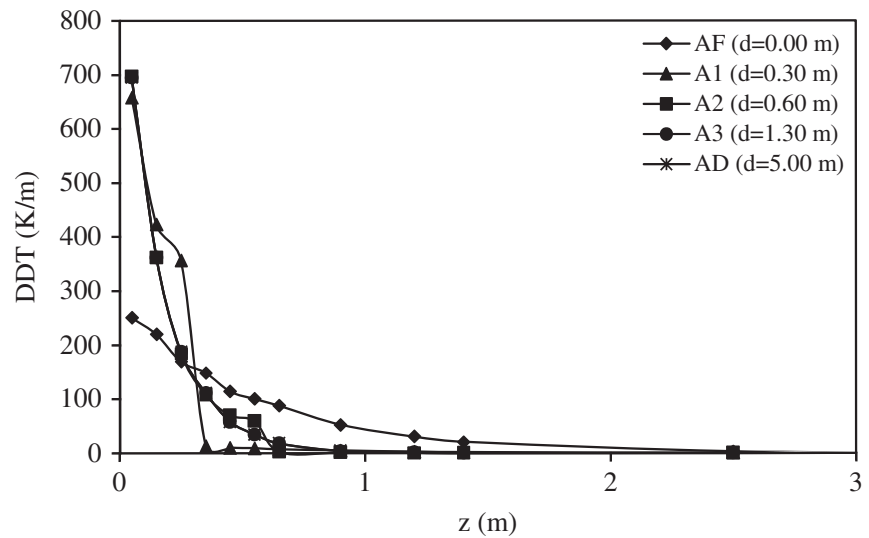

Fig. 7. Derivative of the maximum temperature-time oscillation, DDT, versus depth in soil analogues A.

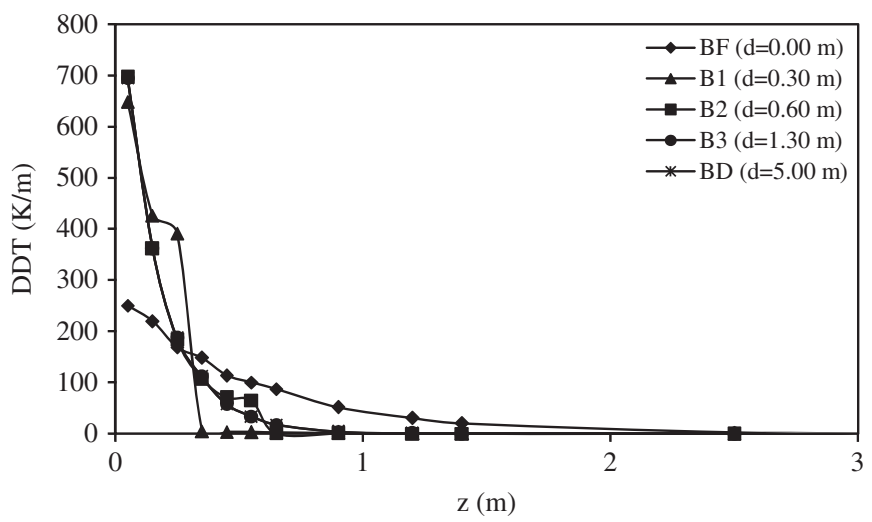

Fig. 8. Derivative of the maximum temperature-time oscillation, DDT, versus depth in soil analogues B.

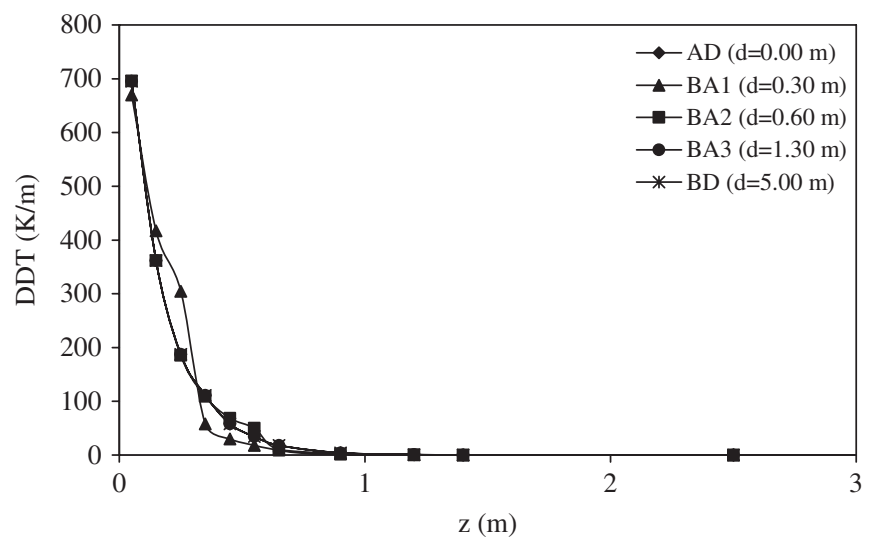

Fig. 9. Derivative of the maximum temperature-time oscillation, DDT, versus depth in soil analogues BA.

$z=1.20 \mathrm{~m}$ to $0.03 \mathrm{~K} \mathrm{~m}^{-1}$ at $z=1.40 \mathrm{~m}$ for soil A3. The conclusion of the exam of the data reported in Table 6 is that DDT decreases by more than one order of magnitude at the boundary between dry and frozen soil.

The exam of the DDT data at the same depth, i.e. on each row of the Table, shows that DDT decreases with the 
increase in the depth $d$ of the dry layer if the soil is frozen. The variation of DDT with the depth $d$ of the dry layer is different if the layer is dry. Indeed, in a dry layer DDT has a maximum and then a nearly constant value with the increase in $d$.

Fig. 7 presents DDT in soils A. The trend of DDT with the depth of the dry layer $d$ is more complex than the corresponding value of DT in Fig. 4. In the frozen layer of the soil the value of DDT decreases with the increase in the dry layer $d$. In the dry layer of the soil the value of DDT increases up to a maximum and then remains nearly constant with the increase in the layer $d$ of the dry soil.

\subsection{Soils $B$}

Table 7 and Fig. 8 present the values of DDT for soils B. At the boundary between dry and frozen soil DDT decreases from $391.5 \mathrm{~K} \mathrm{~m}^{-1}$ at $z=0.25 \mathrm{~m}^{-1} 5.1 \mathrm{~K} \mathrm{~m}^{-1}$ at $z=0.35 \mathrm{~m}$ for soil $\mathrm{B} 1$, from $65.4 \mathrm{~K} \mathrm{~m}^{-1}$ at $z=0.55 \mathrm{~m}$ to $0.8 \mathrm{~K} \mathrm{~m}^{-1}$ at $z=0.65 \mathrm{~m}$ for soil $\mathrm{B} 2$, from $1 \mathrm{~K} \mathrm{~m}^{-1}$ at $z=1.20 \mathrm{~m}$ to $0.01 \mathrm{~K} \mathrm{~m}^{-1}$ at $z=1.40 \mathrm{~m}$ for soil B3. The conclusion of the exam of the data reported in Table 7 is that DDT decreases by more than one order of magnitude at the boundary between dry and frozen soil.

The exam of the DDT data at the same depth, i.e. on each row of the table, shows that DDT decreases with the increase in the depth $d$ of the dry layer if the soil is frozen. The variation of DDT with the depth $d$ of the dry layer is different if the layer is dry. Indeed, in a dry layer DDT has a maximum and then a nearly constant value with the increase of $d$.

Fig. 8 presents DDT in soils B. In the frozen layer of the soil the value of DDT decreases with the increase of the dry layer $d$. In the dry layer of the soil the value of DDT increases up to a maximum and then remains nearly constant with the increase in the layer $d$ of dry soil, as already observed in Fig. 7.

\subsection{Soil $B A$}

Table 8 and Fig. 9 present the values of DDT for soils B A. The variation of DDT at the boundary between the two dry soils, B and A, is smaller than at the boundary between dry and frozen soil, as in the soils A and B, because the thermal conductivities of the dry soils $\mathrm{A}$ and $\mathrm{B}$ are closer. Table 8 shows that DDT decreases from $304.5 \mathrm{~K} \mathrm{~m}^{-1}$ at $0.25 \mathrm{~m}$ to $57.9 \mathrm{~K} \mathrm{~m}^{-1}$ at $0.35 \mathrm{~m}$ for soil BA1, from $50.0 \mathrm{~K} \mathrm{~m}^{-1}$ at $0.55 \mathrm{~m}$ to $9.4 \mathrm{~K} \mathrm{~m}^{-1}$ at $0.65 \mathrm{~m}$ for soil BA2, from $0.9 \mathrm{~K} \mathrm{~m}^{-1}$ at $1.20 \mathrm{~m}$ to $0.1 \mathrm{~K} \mathrm{~m}^{-1}$ at $1.40 \mathrm{~m}$ for soil BA3.

Fig. 9 presents the values of DDT versus depth for soils BA. DDT is practically independent on the layer $d$ of the dry soil B, as already seen for DT in Fig. 6 .

\section{Conclusions}

The measurement of the maximum temperature-time oscillation during a Martian day, DT, inside a Martian soil analogue can be used to evaluate the derivative of DT with depth $z$, i.e. DDT $=\mathrm{d}(\mathrm{DT}) / \mathrm{d} z$. The first conclusion comes from the observation of the variation of DDT with the depth $z$. At the boundary between a dry and a frozen layer DDT decreases with the depth $z$ of more than one order of magnitude. On the contrary, the decrease of DDT with the depth $z$ at the boundary between two dry soils with different porosity $p$ is smaller than one order of magnitude. The variation of DDT with the value $d$ of the top dry layer is dependent on the status of the layer. DDT decreases with the increase of $d$ if the layer is frozen while DDT increases with $d$ in the upper dry layer up to a maximum and then is almost constant. DDT is practically independent of $d$ in soil analogues made of two dry layers with different porosity.

In conclusion, the present method can be used to evaluate the presence of frozen layers from the measurements of the temperature-time oscillations inside the Martian regolith.

\section{Acknowledgement}

The present work has been supported partially by the European Space Agency (ESA).

\section{References}

Böttger, H.M., Benkhoff, J., Forget, F., Lewis, S.R., Read, P.L., Foing, B.H., Helbert, J., 2005. Subsurface water ice stability on Marscurrent and past climates, Geophysical Research Abstracts, vol. 7, 08884, SRef-ID: 1607-7962/gra/EGU05-A-08884, European Geosciences Union.

Boynton, W.V., et al., 2002. Distribution of hydrogen in the near surface of Mars: evidence for subsurface ice deposits. Science 297, 81-85.

Feldman, W.C., et al., 2002. Global distribution of neutrons from Mars: results from Mars Odyssey. Science 297, 75-78.

Gori, F., 1983. A Theoretical model for predicting the effective thermal conductivity of unsaturated frozen soils. In: The Fourth International Conference on Permafrost, Fairbanks (AK), pp. 363-368.

Gori, F., Corasaniti, S., 1999. Considerations on a theoretical method for the prediction of the thermal conductivity of porous media. In: The 17th UIT National Heat Transfer Conference, Ferrara (Italy), vol. II, pp. 683-694.

Gori, F., Corasaniti, S., 2001. Theoretical prediction of the effective thermal conductivity of particulate materials in extraterrestrial conditions and of foams at low density. Microgravity Space Station Utilization 2 (2-3-4), 23-24.

Gori, F., Corasaniti, S., 2003. Experimental measurements and theoretical prediction of the thermal conductivity of two- and three-phase water olivine systems. Int. J. Thermophys. 24 (5), 1339-1353.

Gori, F., Corasaniti, S., 2004. Theoretical prediction of the thermal conductivity and temperature variation inside Mars soil analogues. Planet. Space Sci. 52, 91-99.

Gori, F., Corasaniti, S., 2006. Thermal properties and temperature variations in Martian soil analogues. In: Maravell, N.S. (Ed.), Space Science: New Research. ISBN 1-60021-005-8 (Chapter 6). 
Mellon, M.T., Feldman, W.C., Prettyman, T.H., 2003. Theory of ground ice on Mars and implications to the neutron leakage flux. In: American Geophysical Union (AGU), Fall Meeting 2003, Abstract \#C12C-03.

Mellon, M.T., Feldman, W.C., Prettyman, T.H., 2004. The presence and stability of ground ice in the Southern Hemisphere of Mars. Icarus 169, 324-340.

Presley, M.A., Christensen, P.R., 1997. Thermal conductivity measurements of particulate materials, two results. J. Geophys. Res. 102 (3), $6551-6566$.

Prettyman, T.H., Feldman, W.C., Mellon, M.T., McKinney, G.W., Boynton, W.V., Karunatillake, S., Lawrence, D.J., Maurice, S., Metzger, A.E., Murphy, J.R., Squyres, S.W., Starr, R.D., Tokar,
R.L., 2004. Composition and structure of the Martian surface at high southern latitudes from neutron spectroscopy. J. Geophys. Res. 109, E05001.

Richter, L., Sims, M., Economou, T., Stoker, C., Wright, I., Tokano, T., 2004. A subsurface soil composition and physical properties experiment to address Mars regolith stratigraphy. In: Second Conference on Early Mars, October 11-15, Jackson Hole, Wyoming, p. 8038.

Tarnawski, V.R., Gori, F., 2002. Enhancement of the cubic cell soil thermal conductivity model. Int. J. Energy Res. 26, 143-157.

Van Wijk, W.R., 1963. Physics of Plant Environment. North-Holland Publishing Company, Amsterdam. 